\title{
Liberalismo desenfrenado y pandemia: la encrucijada entre el tecnoautoritarismo y una nueva organización social
}

\author{
Giovanni Dosi
}

\section{Resumen}

En este ensayo se analizan algunas tendencias del capitalismo mundial previas a la pandemia y ciertas especificidades de ella que colocarían a la economía mundial en la encrucijada entre mantener el tecnoautoritarismo vigente en la gobernanza de los países y un cambio en la organización social. Se plantea que la pandemia surge en un contexto de creciente tecnologización y una frágil arquitectura socioeconómica, que se fue debilitando desde la irrupción del neoliberalismo en los años ochenta y, sobre todo, a partir de la crisis financiera de 2008. Se analizan, como tendencias principales: la globalización y la emergencia de China, el estancamiento salarial y la brecha entre productividad y salarios, junto con la explosión de la tasa de beneficio, además de los beneficios corporativos (financieros y no financieros) y la convergencia entre inteligencia artificial y automatización. Se plantean, además, un conjunto de lecciones que se pueden extraer de la pandemia.

\section{Palabras clave}

COVID-19, virus, epidemias, aspectos económicos, aspectos sociales, estructura social, condiciones económicas, liberalismo, salud, política sanitaria, empleo, política de empleo, horas de trabajo, política económica, política social

\section{Clasificación JEL}

F60, P11, D33, O33

\section{Autor}

Giovanni Dosi es Profesor del Instituto de Economía de la Scuola Superiore Sant’Anna en Pisa (Italia). Correo electrónico: giovanni.dosi@santannapisa.it. 


\section{Introducción}

Me gustaría comenzar por plantear algunas premisas generales y otras específicas sobre la reciente pandemia de COVID-19 y las respuestas institucionales que ha suscitado.

En primer lugar, la enfermedad por coronavirus llega a una sociedad occidental caracterizada por la fragilidad de su arquitectura social y su estructura económico-tecnológica. Al mismo tiempo, China se ha convertido en "la fábrica del mundo" y adquiere un peso cada vez mayor entre los líderes tecnológicos y políticos mundiales.

En segundo lugar, la estructura socioeconómica que sostuvo los "años gloriosos" del capitalismo de posguerra ya se había deteriorado por razones endógenas en los años setenta y fue devastada por la conjunción entre la afirmación del fanatismo liberal (Reagan y Thatcher) y la caída de la Unión Soviética (que para todos los ciudadanos del mundo fuera de su órbita representó una protección milagrosa contra la rapacidad de los capitalistas).

En tercer lugar, la crisis de 2008, que de crac financiero se convirtió inmediatamente en una recesión de la economía real, tuvo como respuesta, en el mejor de los casos (como en los Estados Unidos), un intento de recuperar una situación de "normalidad" mediante políticas fiscales keynesianas y políticas (anti)redistributivas dirigidas a socializar las pérdidas financieras. En el peor de los casos (Europa), las políticas de austeridad masoquistas implementadas solo han causado un crecimiento anémico en los países más fuertes y un estancamiento persistente en los demás.

Y entonces llega la pandemia de COVID-19, que al principio se subestimó ampliamente para luego estallar en un pánico colectivo. Esto entra en cortocircuito con la incompetencia de la mayor parte de las clases políticas que, sobre todo en presencia de un sistema de salud desastroso, recurre a la respuesta más simple y burda, sumamente dolorosa desde el punto de vista social y no muy eficaz desde el punto de vista epidemiológico a largo plazo: aislamiento y ejército en las calles en lugar de pruebas masivas y tratamiento precoz.

Pero empecemos por examinar algunas tendencias económicas y sociales preexistentes.

\section{Algunas tendencias ${ }^{2}$}

\section{La globalización y el ascenso de China como "fábrica del mundo"}

Después de 40 años de presión política internacional hacia el "libre comercio", la liberalización de los movimientos de capital ha sido una de las principales causas de la inestabilidad económica de los últimos 20 años (Stiglitz, 2002).

Al mismo tiempo, los profundos y vertiginosos cambios en la división internacional del trabajo con el surgimiento de China como "polo industrial del mundo" han reducido significativamente la solidez de las clases trabajadoras en el Occidente desarrollado y, en particular, su poder de negociación.

\footnotetext{
1 La mayor parte de estos temas se examina de manera más detallada en Dosi (1984) y Freeman y Soete (1994) y en los más recientes Dosi y Virgillito (2019, 2020a y 2020b), Dosi y otros (2020) y Bellomo y otros (2020).

2 Véanse más detalles en Dosi y Virgillito (2019), trabajo en el que se basa ampliamente esta sección.
} 


\section{El estancamiento de los salarios y la creciente divergencia entre el aumento de la productividad y el crecimiento de los salarios}

Aunque a ritmos diferentes, a partir de la década de 1980 los salarios medios (especialmente los más bajos) comenzaron a crecer menos que la productividad en casi todos los países. En consecuencia, la proporción de los salarios en el producto interno bruto (PIB) también disminuyó.

\section{La explosión de los beneficios, especialmente los financieros}

Esta es la simetría obvia del punto anterior. Los datos estadísticos incluso subestiman el fenómeno porque las remuneraciones de los altos directivos tradicionalmente se incluyen entre los "sueldos y salarios" cuando, claramente, la dinámica remunerativa de un alto directivo no tiene nada que ver con la de un trabajador de la producción. Además, el aumento de la participación de los beneficios financieros ha sido mucho más que proporcional.

\section{La explosión de los ingresos financieros y no financieros}

La "financierización" de las economías incluye ciertamente los ingresos financieros en sentido estricto: los nombres Goldman Sachs, J.P. Morgan y Morgan Stanley, entre otros, son conocidos por todos. Menos conocidos son los cientos de fondos de capital privado (private equities) que especulan como langostas - la definición es de un famoso primer ministro - en adquisiciones y fraccionamientos de empresas en la economía real, sin importar el daño a la economía a largo plazo.

Pero estas rentas van mucho más allá de eso.

Quisiera señalar los ingresos derivados de las patentes, en primer lugar las patentes farmacéuticas (véase más adelante), y luego, de manera más general, los ingresos derivados de la expansión de formas de organización "de mercado" a esferas que antes, al menos en Europa, eran casi exclusivamente públicas, como la educación, la investigación y la salud. Por último, cabe mencionar también los ingresos "basados en la información" de los grandes oligopolistas como Google, Facebook y Amazon, entre otros.

\section{La convergencia tecnológica entre la inteligencia artificial y la automatización (tendencia más reciente)}

Estamos solo al principio, pero este proceso promete cambiar radicalmente las condiciones de trabajo en las "fábricas" y "oficinas", aumentando significativamente el papel de las llamadas plataformas, incrementando la polarización de las condiciones de trabajo y los salarios entre los trabajadores y reduciendo drásticamente su poder de negociación.

\section{Y llega el COVID-19...}

Es en presencia de estas tendencias a más largo plazo que llega la pandemia. Aquí también son necesarias algunas premisas. Seguramente el COVID-19 no es en absoluto una gripe trivial, pero 
tampoco es la peste negra del siglo XIV. Aunque el mundo ciertamente se enfrenta a una crisis de salud sin precedentes, la pandemia de COVID-19 no se encuentra, en términos de mortalidad absoluta y relativa, entre las peores de la historia, especialmente gracias a las mejores condiciones de atención médica que en el pasado. La "Española" de 1919 alcanzó una mortalidad del 2,73\%, pero la peor, con mucho, fue la peste negra del siglo XIV que exterminó a más del $40 \%$ de la población de Europa.

Y a diferencia de este último, el impacto económico directo de la pandemia actual es y habría sido menor.

La peste del siglo XIV tuvo un gran impacto económico y en sentido igualitario, porque la reducción de casi un tercio de la fuerza de trabajo provocó un fuerte aumento de los salarios, mientras la muerte de los herederos directos de los bienes inmuebles condujo a su devaluación masiva.

Hoy, el principal impacto de la pandemia deriva de las propias medidas de contención y supresión y de su interacción con las desigualdades económicas y sociales preexistentes. Las primeras tienden a amplificar las segundas.

Así, en muchos países, incluidos aquellos con un sistema de salud público y universal, aunque empobrecido por décadas de recortes atroces (como Italia, Francia y el Reino Unido), incluso la ubicación del hogar por sí sola a menudo influye en el acceso a la atención hospitalaria.

Sin embargo, la tragedia más profunda se observa en países con una asistencia sanitaria predominantemente privada, como los Estados Unidos, donde los ingresos y el color de la piel son excelentes predictores de la probabilidad de vivir o morir a causa del virus.

Y luego vienen los efectos del confinamiento en los ingresos presentes y futuros, en la probabilidad de despido, en la posibilidad de trabajar a distancia...

Todo esto se exacerba para los trabajadores de la economía "informal" que, cabe señalar, representan casi el 50\% en el sur de Italia y seguramente más en los países en desarrollo, y para los inmigrantes irregulares.

Quedarse en casa parece ser un privilegio para quienes trabajan en una empresa o un organismo público preparados para el teletrabajo (más la excepción que la regla) y para quienes tienen algunos ahorros acumulados y por lo tanto pueden darse el lujo de no trabajar. ¿Y para el resto? En el mejor de los casos, vacaciones obligatorias y licencia parental pagada al 50\%; en el peor de los casos, importantes reducciones de los ingresos por trabajo y, en muchos casos, trabajo a tiempo parcial y precario.

Una de las muchas y amargas lecciones que la pandemia nos está enseñando es la manera en que la diferencia en los derechos laborales entre empleados públicos, empleados privados, trabajadores autónomos y por cuenta propia se vuelve inmanejable y aún menos tolerable en una emergencia sanitaria. Las huelgas en Italia de los últimos meses en el sector manufacturero han estado claramente motivadas por la incomprensible falta de medidas de protección de seguridad, por ejemplo, la reducción de los turnos de trabajo para garantizar el espacio entre los trabajadores. Trabajar menos y trabajar todos (repartidos en varios turnos con menos personas) por el mismo salario, podía ser, y sigue siendo, una solución para asegurar la capacidad de producción, el salario y el empleo, pero no ha habido ninguna iniciativa en esa dirección. Han proliferado las ordenanzas contra las aglomeraciones de personas pero nadie dice nada sobre la responsabilidad de las empresas de garantizar las condiciones de seguridad con dispositivos de protección.

A las desigualdades económicas se suman las desigualdades sociales y territoriales.

¿Es posible compensar el cierre de las escuelas con la educación en línea? Lamentablemente, la educación en línea no puede establecerse en diez días, grandes sectores de la población carecen de conexión a la red y de instrumentos adecuados para acceder a ella y los programas no están ni remotamente estructurados. En cualquier caso, nunca será como la educación presencial, a menos que el objetivo sea formar una sociedad de sujetos con competencias muy diferentes y niveles de habilidades 
polarizados, lo que también implicaría una polarización de las "oportunidades". La enseñanza a distancia es una fuente de grandes brechas de aprendizaje entre estudiantes de diferentes orígenes socioeconómicos y aumenta el riesgo de aislamiento para los estudiantes que viven en contextos marginales.

Obviamente no faltan anécdotas sobre experimentos (casi) exitosos, tal vez en las escuelas y colegios de los barrios más ricos, pero también deberíamos preocuparnos y preguntarnos si la educación a distancia funciona para los estudiantes de barrios más pobres y marginados, que suelen tener una tasa de asistencia escolar muy baja.

En aulas ya afectadas por la pobreza generalizada y las brechas sociales, la escuela, también como edificio, representa la última oportunidad, no solo de intercambio social, sino de promoción de igualdad sustancial. Esto no necesariamente se manifiesta en la práctica y sabemos muy bien que las condiciones de ingresos y culturales de las familias son la variable que más influye en el logro real de los resultados escolares y la trayectoria de estudio. Sin embargo, la educación en línea plantea una nueva brecha tecnológico-infraestructural que se asienta en las brechas sociales, territoriales y económicas.

En todos los países, incluida Italia, se han introducido medidas compensatorias y de apoyo a: i) los ingresos (transferencias, subsidios de desempleo, pagas extraordinarias); ii) las empresas (de nuevo transferencias, desgravaciones fiscales, créditos garantizados, posibles participaciones accionarias); iii) las rentas, sobre todo, mediante odiosas transferencias, con alquileres básicamente pagados por el Estado por un período, al igual que los créditos de los bancos, también garantizados por el Estado.

Al final, a casi un año del primer brote de COVID-19, los países se encuentran con paquetes de medidas no siempre coherentes, formuladas y agrupadas por una plétora de burócratas que representan intereses en conflicto (donde, por supuesto, los banqueros están mucho mejor representados que los desempleados o los vendedores ambulantes).

El resultado social varía entre una protección muy limitada o inexistente para los trabajadores del sector informal y los pobres sin trabajo (la situación es aún peor para los inmigrantes); una protección limitada para los trabajadores fijos y las pequeñas empresas; una protección mayor para las grandes empresas no financieras (basta pensar en las garantías multimillonarias solicitadas por las grandes empresas europeas), hasta el paracaídas casi total para los ingresos financieros e inmobiliarios.

\section{IV. ¿Y las libertades civiles?}

Los intentos de contener y suprimir el contagio suponen inevitablemente alguna sugerencia o medida de contención coercitiva. Conforme la Constitución, la libertad y la salud son dos derechos fundamentales y, naturalmente, las limitaciones a la primera solo pueden ser estrictamente proporcionales a necesidades muy urgentes con respecto a la segunda.

Por el contrario, me parece que ha habido una peligrosa convergencia entre la incompetencia organizativa total (¿dónde se producen las mascarillas?, ¿quién nos vende los reactivos?, ¿y los respiradores?, ¿y cómo se amplían las unidades de cuidados intensivos?...) y una especie de sentimiento común amplificado en el pánico colectivo que yo llamaría "autoritarismo médico-ético".

A todo esto, las autoridades - notoriamente incompetentes en materia de epidemiología pero apoyadas por presuntos "expertos" que no aparecieron de la nada pero ciertamente tampoco vinieron del olimpo de la ciencia - regulan nuestra vida cotidiana.

Se trata de una extraña coalición ideológica, que me resulta difícil de explicar, entre un establishment económico históricamente indiferente a las libertades personales ("se puede salir de la casa solo para ir a trabajar") y una especie de "pseudoizquierda ética" ("estamos actuando por su bien, así que obedezcan y cállense"). Y así la paradoja es que los abanderados de la reivindicación de los 
límites de la interferencia estatal se han convertido en los grupos de extrema derecha, los anticiencia y los teóricos de la conspiración.

Aquí hay un problema muy serio. Los modelos de contención de la pandemia basados en el control social, que las nuevas tecnologías de vigilancia hacen muy fácil (y ante las cuales las democracias liberales tienen muy pocos anticuerpos porque han sido debilitadas por la silenciosa y generalizada intrusión de las grandes plataformas digitales) se están volviendo naturales y socialmente aceptables.

\section{Las políticas y una posible encrucijada histórica}

La experiencia de la pandemia enseña algunas lecciones obvias sobre las políticas que se han de adoptar ${ }^{3}$.

La primera, muy evidente, es que hay que revitalizar y fortalecer el sistema de salud público y universal, arruinado por la "dieta" a que se ha sometido al sector público en general y a la salud en particular, en nombre de un liberalismo devastador que también llegó a socavar derechos universales como la salud, la educación y la generación de conocimientos. Se dice que la lucha contra la pandemia es una "guerra". Pues bien, las guerras siempre han sido demasiado serias para dejarlas a los mercados.

En segundo lugar, un corolario importante de este punto es que el Estado debe recuperar la capacidad de planificar la producción de bienes y servicios esenciales. Un par de meses después del ataque a Pearl Harbour, los Estados Unidos podían producir alrededor de un tanque de guerra por hora. Después de dos meses de pandemia, la administración pública de la mayoría de los países pertenecientes y no pertenecientes a la Organización para la Cooperación y el Desarrollo Económicos (OCDE) no era capaz de producir mascarillas, iy ni siquiera sabía exactamente quién podía fabricarlas!

En tercer lugar, la pandemia puso de relieve la dramática ineficiencia de un sistema de generación de conocimientos médicos y farmacológicos, en el que la mayor parte del costo recae en el sector público, mientras la dirección de la explotación de esos conocimientos y los ingresos conexos se atribuyen al privado. Como se expone en Cimoli y otros (2014), es urgente que el aparato público desarrolle competencias autónomas sobre los medicamentos y las vacunas hasta la fase de pruebas en seres humanos y que, en consecuencia, se reduzcan drásticamente las posibilidades de apropiación de los enormes ingresos garantizados por los "derechos de propiedad intelectual" por parte de las empresas farmacéuticas.

Sin embargo, hay políticas y programas cuya urgencia se ha visto solo acentuada por la pandemia, pero que obedecen a las tendencias a largo plazo mencionadas anteriormente.

Hace un año señalábamos (Dosi y Virgillito, 2019), dramatizando, dos arquetipos en la encrucijada que todas las sociedades están afrontando o a punto de afrontar entre una forma de organización socioeconómica que podríamos llamar, con Freeman (1992), la economía de la esperanza y otra que hemos llamado la sociedad Blade Runner (por la película homónima).

En el debate político, finalmente se está reconociendo cada vez más que hay que hacer algo ante el fuerte aumento de la desigualdad, el potencial desempleo masivo, el deterioro de las condiciones de trabajo y la erosión del estado de bienestar. Sin embargo, las discusiones tienden a ser parciales (con el enfoque de abordar un problema a la vez) y con demasiada frecuencia están radicadas en el paradigma interpretativo de la ortodoxia económica - basado en la idea de que las políticas, de ser realmente necesarias, deben justificarse por "fricciones de mercado", rigideces o, en el peor de los casos, "fallas de mercado" -, en el supuesto de que, dejados a su suerte, los mercados pueden en general cuidarse a sí mismos de manera eficiente y, en consecuencia, cuidarnos a todos. Así, por ejemplo, no puede haber - por definición - desempleo tecnológico a largo plazo.

3 Véase un análisis más detallado en Pianta (2020). 
Por supuesto, es necesario evaluar la eficacia y las posibles concesiones que suponen distintos conjuntos de políticas en materia de, por ejemplo, redistribución, impuestos en un mundo globalizado y digitalizado, educación, formación, empleo, innovación e industria, pero debemos considerarlas conjuntamente.

Algo aún más importante, es que el debate debe situarse en el contexto más amplio de las nuevas relaciones entre los seres humanos y el trabajo y entre las personas y las instituciones. Distintas políticas conducirán a diferentes configuraciones del Estado y de las instituciones intermedias, con diferentes estructuras que van desde los "Estados minimalistas" a los "Estados niñera", diversas combinaciones entre formas de acción individuales y colectivas y entre la prestación pública o de mercado de los servicios colectivos.

Las diferentes combinaciones tienen consecuencias claramente distintas, no solo en términos de crecimiento de los ingresos, sino también, y al menos con la misma importancia, en términos de inclusión social, distribución del trabajo y los ingresos y, en definitiva, del poder.

En primer lugar, por primera vez desde principios del siglo XX, se está volviendo a formar en los países actualmente industrializados de Occidente un subproletariado (lumpemproletariado, como diría Marx) formado por personas que no pueden trabajar, trabajadores precarios y a menudo clandestinos, muchos trabajadores de las "plataformas", en muchos aspectos "no ciudadanos" (¿recuerdan las dificultades que tuvieron y tienen los sin techo para recibir subsidios o acceso al sistema de protección social?) Hasta hace poco tiempo, leer a Balzac o a Dickens era leer novelas históricas. ¡Hoy tenemos que volver a leerlos como crónicas de actualidad!

Y esta es una parte cada vez mayor de la sociedad de la que tenemos que ocuparnos, de lo contrario pronto llegaremos a una sociedad de tipo Blade Runner, a la que se hacía referencia antes.

Pasemos a los trabajadores, por así decirlo, "de verdad", en el sentido minimalista de "existentes", que tienen cobertura de los sistemas de previsión pública y quizás un contrato de trabajo "a tiempo indeterminado" (con la trágica ironía que tiene este adjetivo después de las reformas, en Italia y en otras partes, de flexibilización de los mercados de trabajo). ¿Qué podemos hacer?

Ciertamente, los programas alternativos relativos a las instituciones del mercado laboral incluyen la codeterminación, por la que los trabajadores ejercen cierto control sobre las estrategias de la empresa, y, en lo que respecta a los ingresos, se necesitan con urgencia un ingreso básico universal y un salario mínimo. Naturalmente, cada alternativa tiene consecuencias distributivas y sociales muy diferentes. Por ejemplo, las medidas de ingeniería microinstitucional que implican la copropiedad de los trabajadores, la participación en los beneficios o incluso la codeterminación al estilo alemán ponen la carga de la redistribución en el empleador o la empresa individual. Si bien es probable que sean bastante eficaces "a nivel local", presentan el gran riesgo de crear una brecha entre una élite de trabajadores y el resto. Aunque tienen la ventaja de aumentar la participación de los salarios en los ingresos producidos y redistribuir los incrementos de productividad a nivel empresarial, tienen la desventaja de exacerbar las disparidades entre los grupos de trabajadores y son relativamente ineficaces para hacer frente al desempleo agregado.

Por el contrario, el extremo inferior de la distribución de los ingresos debe abordarse mediante programas más universales, como las distintas formas de ingresos básicos. Sin embargo, estas no están exentas de limitaciones. Aunque proporcionan una red de seguridad para todos los ciudadanos, su aplicación tiende a ser - en el mejor de los casos - neutral en lo que respecta a la redistribución general de los ingresos. En efecto, el ingreso básico suele apoyarse junto con una gran reducción del estado de bienestar, que implica la transformación de bienes públicos, como la salud y la educación, en transferencias de ingresos (privadas). Vale la pena recordar que Milton Friedman fue uno de los primeros partidarios del impuesto negativo universal sobre la renta. Además, los programas de ingresos básicos pueden ser objeto de distorsiones políticas, pues el derecho a acceder a ellos puede estar vinculado a 
la ciudadanía, lo que plantea cuestiones fundamentales de trato discriminatorio con respecto al conjunto de "no ciudadanos". El aumento del nivel de ingresos mínimos también podría ayudar a establecer un umbral mínimo para la participación del trabajo, que está en caída libre. Sin embargo, habría que ser cuidadosos de no debilitar el poder de negociación de los sindicatos y amenazar la organización colectiva de los trabajadores. No puede ser la única medida redistributiva.

A este respecto, los impuestos deben volver a desempeñar un papel importante. Deberían aplicarse nuevas y antiguas formas de tributación progresiva. Se debe prestar especial atención a la comprensión tanto de las dinámicas de la base imponible como de las formas en que se deben gravar los diferentes tipos de ingresos, ya sean beneficios o salarios, y las rentas (financieras y no financieras). La furia promercado de las últimas décadas se ha combinado con una ideología colectiva contra los impuestos que ha reducido en gran medida el impacto redistributivo de las políticas fiscales y la prestación universal de servicios. Hay que invertir esta tendencia y encontrar nuevas combinaciones de tipos impositivos, de manera que los alquileres y la riqueza en general estén más gravados que los beneficios y estos últimos más gravados que los salarios. Es cierto que cada vez se vuelve más difícil captar rentas y beneficios, no solo porque no hay voluntad política para hacerlo, sino también debido a sus características y a su aparente falta de domicilio geográfico. Sin embargo, los medios técnicos existen, pues los beneficios y los flujos financieros en general pueden monitorearse desde el país de origen hasta el país de destino, generalmente un paraíso fiscal.

Asimismo, también los objetos de los impuestos pueden cambiar. Deberían al menos discutirse nuevas formas de tributación, incluidos el "impuesto a los robots", el "impuesto a los bits" y el "impuesto a la web". Algunos estudiosos sugieren que quien posee los robots gobierna el mundo (Freeman, 2015).

La República de Corea ha introducido recientemente un impuesto sobre los robots y esta cuestión también se está debatiendo en el Parlamento Europeo. Sin embargo, si bien es probable que un impuesto sobre los robots retrase la adopción de tecnologías de sustitución del trabajo humano, todavía no está claro si este debe aplicarse a la propiedad o al uso de los robots. En efecto, parece mucho más razonable gravar con impuestos a los propietarios (por lo tanto, en última instancia, los beneficios que generan los robots). En otra época, la alternativa habría sido entre gravar a las locomotoras o a los magnates de los ferrocarriles: la respuesta es obvia. Además, los robots pueden utilizarse de formas diferentes, muchas de las cuales no apuntan a sustituir sino a integrar las actividades humanas en una amplia gama de sectores, desde la agricultura hasta la industria y el sector de servicios (entre los ejemplos figuran las aplicaciones médicas y biorrobóticas).

Otra propuesta, el "impuesto a los bits", forma parte del discurso político desde principios de los años noventa (Soete y Kamp, 1996). A medida que las transacciones y los ingresos que producen se vuelven cada vez más "intangibles", la base imponible debería pasar de las unidades físicas a las digitales (es decir, a los bits de información transmitidos). El impuesto a la web, que grava las transacciones digitales, puede considerarse una forma de impuesto a los bits. La tributación de las plataformas es otra cuestión abierta de gran importancia. Las plataformas utilizan cada vez más recursos individuales (como los apartamentos en el caso de Airbnb) para obtener beneficios empresariales. Estos activos, que están muy distribuidos, generan beneficios que, por el contrario, están muy centralizados.

Además de las políticas en materia de ingresos, es necesario concentrarse en las políticas de empleo. Algunas son indirectas e influyen en primer lugar en las características de la oferta de trabajo. Las políticas en materia de educación y formación se incluyen en esta categoría, al igual que las denominadas "políticas activas" del mercado de trabajo, que prevén programas de capacitación para los desempleados y formación continua para los trabajadores, de modo que también puedan superar la eventual obsolescencia de sus capacidades. Si bien no cabe duda de que son esenciales, estas políticas son completamente insuficientes y deben ir acompañadas de políticas más directas (Dosi y otros, 2019). Las empresas no pueden esperar que los empleados que contratan estén formados ad hoc, sino que se las debería alentar a invertir en la mejora del aprendizaje de los 
empleados, sobre todo mediante programas de formación en el empleo. Por el contrario, para hacer frente a los rápidos avances tecnológicos, los trabajadores deberían poseer ante todo una amplia gama de aptitudes no específicas de la actividad. En particular, se debería enseñar y desarrollar un nivel más alto de razonamiento y habilidades abstractas, es decir, lo contrario de lo que muchas empresas exigen a los nuevos empleados.

De acuerdo con un enfoque que se remonta, al menos, al New Deal de Roosevelt, el Estado es el empleador de último recurso. Al contrario de cualquier noción de "Estado minimalista", esta visión implica la creación de programas de trabajo masivo durante las fases de recesión, con la doble ventaja de que los trabajos de utilidad pública se llevan a cabo y las personas reciben un ingreso (Minsky, 1986).

Por último, pero no menos importante, las políticas de empleo incluyen la reducción del horario de trabajo. Esta ha sido también la tendencia secular en los países industrializados desde mediados del siglo XIX, en paralelo con la tendencia secular simétrica hacia la mecanización y la automatización de la producción. Esas políticas se han experimentado recientemente en algunas economías avanzadas con el doble objetivo de crear nuevas oportunidades de trabajo y redistribuir los incrementos de productividad. Ciertamente, esas medidas deberían ir acompañadas de fuertes límites reglamentarios para el trabajo a tiempo parcial involuntario, las formas de trabajo no estándar y los "minitrabajos".

El Estado siempre ha sido un creador de oportunidades de inversión, un patrocinador de programas arriesgados y de la investigación a largo plazo y un generador de innovaciones con una misión concreta (Mazzucato, 2013). Si bien históricamente esto ha sido así sobre todo en los programas militares y espaciales, también ha desempeñado un papel crucial en el desarrollo de la electrónica, la informática, las telecomunicaciones y, antes de ello, de la química sintética y farmacéutica.

Hoy en día debería redoblar ese papel histórico. Un objetivo fundamental debería ser la introducción de políticas ambiciosas que promuevan la creación y el desarrollo de nuevos paradigmas tecnológicos cuyos imperativos solo pueden ser la sostenibilidad ambiental y social y una redistribución más justa del trabajo, los ingresos y, en última instancia, del poder.

En este sentido, el sector público debe recuperar su capacidad no solo de regular, sino también de plasmar profundamente las estrategias de los agentes privados.

En Dosi y Virgillito (2019) se destaca la manera en que las actividades intensivas en información comportan drásticos aumentos de los "rendimientos crecientes", como dicen los economistas, de la información en sí. A su vez, esto tiende a llevar a una estructura (casi) monopolística de la oferta: los casos de Google, Amazon, Facebook, Airbnb y Uber son arquetípicos. ¿Cómo deberíamos hacer frente a las consecuencias socioeconómicas de estas tendencias? Las políticas de competencia son una medida obvia y la Unión Europea ha comenzado recientemente a aplicarlas. ¿Será suficiente? Probablemente no. La historia nos enseña que cuando surgen monopolios "naturales", el Estado debe regularlos de forma rigurosa y exhaustiva, e incluso considerar la nacionalización. En el pasado, este ha sido el caso de las telecomunicaciones y otros servicios públicos. Hoy en día no deberíamos tratar de evitar tales políticas, visto el impulso a la monopolización más fuerte que se haya registrado desde el principio de la historia del capitalismo.

Hoy nos enfrentamos a una encrucijada histórica, tanto en las trayectorias tecnológicas como en las formas de organización socioeconómica. Podemos avanzar hacia una forma de tecnofeudalismo con una sociedad profundamente dividida o hacia una sociedad que comparta colectivamente los beneficios de los avances tecnológicos (como decía Keynes (1931) hace casi un siglo).

El camino que seguiremos dependerá en gran medida del tipo de política que diseñemos e implementemos.

A todo esto, la pandemia constituye, en última instancia, solo un factor de aceleración, y en mi opinión no para mejor. Las emergencias y el miedo casi siempre favorecen la adopción de soluciones 
autoritarias y la situación actual no es una excepción. Algo aún más importante es que parece no haber, al menos en el momento de escribir este breve ensayo (a principios de octubre de 2020), ninguna percepción de la gravedad de la interacción entre una distribución profundamente injusta de los ingresos y las condiciones de vida y las medidas que restringen las libertades sociales e individuales, que a la larga son incompensables y exacerban las propias desigualdades de las condiciones de vida.

Para ilustrar esto de manera dramática, concluyo con una pregunta: según el lector, si en la Alemania de 1933, después de una serie de políticas restrictivas que llevaron la tasa de desempleo a cerca del $20 \%$, Brüning también hubiera introducido medidas de segregación, con otro 10\% de desempleados, incluso motivado por la llegada de la peste negra, ¿cuántos votos habría logrado Hitler? Bueno, la respuesta es fácil, tal vez el $80 \% \ldots$

\section{Bibliografía}

Bellomo, N. y otros (2020), "A multi-scale model of virus pandemic: heterogeneous interactive entities in a globally connected world", Mathematical Models and Methods in Applied Sciences, vol. 2.

Cimoli, M. y otros (eds.) (2014), Intellectual Property Rights: Legal and Economic Challenges for Development, Oxford, Oxford University Press.

Dosi, G. (1984), "Technology and conditions of macroeconomic development", Design, Innovation and Long Cycles in Economic Development, C. Freeman (ed.), Londres, Design Research Publications.

Dosi G. y otros (2020), "Costi e limiti della precauzione suggerita da un discutibile report scientifico", Scienza in Rete, mayo.

- (2019), "What if supply-side policies are not enough? The perverse interaction of flexibility and austerity", Journal of Economic Behavior \& Organization, vol. 162.

Dosi, G. y M. E. Virgillito (2020a), “Tutti uguali davanti alla Pandemia?”, Scienza in Rete, marzo. (2020b), "Covid-19: distanziamento sociale e diritti", Scienza in Rete, marzo.

(2019), "Whither the evolution of the contemporary social fabric? New technologies and old socio-economic trends", International Labour Review, vol. 158, № 4.

Freeman, Ch. (1992), The Economics of Hope: Essays on Technical Change, Economic Growth, and the Environment, Hardcover, septiembre.

Freeman, C. y L. Soete (1994), Work for All or Mass Unemployment: Computerised Technical Change in the Twenty-First Century, Londres, Pinter.

Freeman, R. (2015), "Who owns the robots rules the world", IZA World of Labor, № 5.

Keynes, J. M. (1931), "Economic possibilities for our grandchildren", Essays in Persuasion, J. M. Keynes (ed.), Londres, Macmillan.

Mazzucato, M. (2013), The Entrepreneurial State: Debunking Public Vs. Private Sector Myths, Londres, Anthem Press.

Minsky, H. P. (1986), Stabilizing an Unstable Economy: The Lessons for Industry, Finance and Government, New Haven, Yale University Press.

Pianta, M. (2020), "L'intervento pubblico dopo l'epidemia: progetti, strumenti, conflitti”, mimeografía.

Soete, L. y K. Kamp (1996), "The 'bit tax': the case for further research", Science and Public Policy, vol. 23, № 6.

Stiglitz, J. E. (2002), Globalization and its Discontents, Nueva York, W.W. Norton. 